\title{
Effects of processing parameters on the surface quality of wrought Ni-based superalloy by ultrasonic assisted electrochemical grinding
}

Yucai Ma ${ }^{\mathrm{a}, \mathrm{b}}$,Yingyue Yin ${ }^{\mathrm{a}, \mathrm{b}, \#}$, Jianhua Zhang ${ }^{\mathrm{a}, \mathrm{b}, *}$, Jinxing Huo ${ }^{\mathrm{a}, \mathrm{b}}$

${ }^{a}$ Key Laboratory of High Efficiency and Clean Mechanical Manufacture, Ministry of Education of China, School of Mechanical Engineering, Shandong University, Jinan 250061, China

b National Demonstration Center for Experimental Mechanical Engineering Education, School of Mechanical Engineering, Shandong University, Jinan 250061, China

*Corresponding Author: Jianhua Zhang: jhzhang@sdu.edu.cn

\# Yucai Ma and Yingyue Yin contributed equally to this work.

\begin{abstract}
Ni-based GH625 superalloy has been widely employed in the aerospace industry due to its high strength, outstanding corrosion resistance and high temperature resistance. A novel hybrid processing method of ultrasonic-assisted electrochemical grinding (UAECG) can achieve the high-effective removal rate for difficult-to-process materials and thereby avoids the stray corrosion during the process. This study systematically investigated the electrochemical dissolution behaviors of GH625 alloy at low current density and effects of processing parameters on its surface roughness. A qualitative model was proposed to further reveal its removal mechanism for GH625 alloy during UAECG process. Polarization curves depicted that an efficient and stable electrochemical dissolution was achieved at an appropriate temperature $\left(20^{\circ} \mathrm{C}\right)$ and concentration (10 wt.\%) of $\mathrm{NaNO}_{3}$ electrolyte. The findings also revealed that selective corrosion preferentially occurred on the grain boundary or near the $\mathrm{NbC}$ carbides under
\end{abstract}


different current density corrosion circumstance. Compared with ECG process, the excellent surface quality $(R \mathrm{a}=0.37 \mu \mathrm{m})$ and taper of the small holes (taper $=0.04 \pm$ $0.005^{\circ}$ ) are obtained at the optimized condition of pulse voltage of $5.8 \mathrm{~V}$, feed rate of $0.6 \mathrm{~mm} / \mathrm{min}$, cathode speed of $12 \mathrm{kr} / \mathrm{min}$ and ultrasonic drive amplitude of $60 \%$ by UAECG technology.

Keywords: GH625, ultrasonic-assisted electrochemical grinding, polarization curves, processing parameters, surface roughness.

\section{Introduction}

Ni-based GH625 superalloy has been widely used in manufacturing high temperature components (e.g. turbine discs and blades of aero engines) [1] industry due to its high strength, outstanding corrosion resistance and high temperature resistance [2]. However, there existed many defects for traditional processing methods such as low processing efficiency, serious tool wear, high frictional heat and residual stress, which were hardly beneficial for the processing of difficult-to-machine materials. A series of new processing technologies were thus proposed such as laser processing, electric discharge processing, electrochemical processing and high-speed water jet processing [3-5]. Generally, nontraditional machining exhibits many advantages such as high machining efficiency and accuracy, low tool wear and low frictional heat $[6,7]$.

Due to its advantages of high material removal rate, reduced tool wear, lower residual stress [8-11], electrochemical machining (ECM) has thus become an extensive processing technique for fabricating various difficult-to-cut Ni-based superalloys [12]. It employs the principle of anodic dissolution and thereby bypasses the limitations of the alloy's mechanical properties [13, 14]. Rolf Schuster et al. [15] found that the location accuracy and dimensional accuracy of workpieces have remarkably improved using ultra-short pulse power for electrochemical machining and finally achieved the machining accuracy of submicron. Se Hyun Ahn et al. [16] used the high-frequency pulse power with tens of nanosecond pulse width to carry out the experiment of electrochemical drilling for micro-pores, and studied the effects of peak 
voltage, period and pulse width on the machining localization of micro-pores. However, the limitation of application for the ECM is due to the low machining accuracy, unfit tool shapes and insufficient processing parameters control. Due to its high machining accuracy, excellent surface quality and good machining stability, electrochemical grinding (ECG) can offset the process defects during ECM process. Over the past few years, several studies have focused on the influence of process and processing parameters on the surface integrity of processing. Yasuo Kimoto et al [17] were conducted to process disc-shaped workpieces and cylindrical workpieces and obtained sub-micron processing accuracy using ECG technology. Stanislaw and Zaborski [18] verified the superiority of electrochemical grinding from the perspective of energy consumption, and found that the energy consumption of electrochemical grinding was much lower than that of mechanical grinding. Although the processing efficiency of the workpieces was improved using ECG technology, generation of large dimensional accuracy deviations always exist due to severe stray corrosion during ECG process. Fortunately, ultrasonic-assisted electrochemical grinding processing technology (UAECG) was based on the cavitation effect of ultrasonic vibration to promote the circulation of electrolyte and the discharge of electrolytic products and remove the passivation film on the surface of the workpiece on the processing area, thereby improving processing efficiency and stability [19]. S.S. Li, et al was conducted to compare and analyze the difference in cutting force of workpieces between UAECG technology and ultrasonic-assisted pulse electrochemical grinding processing technology. The results showed that the normal stress and tangential stress of ultrasonicassisted electrochemical grinding are respectively reduced by about $57 \%$ and $56 \%$ in comparison with that of traditional grinding [20-22].

The microstructure feathers obviously affected the anodic dissolution behavior of metals. Yin et al. found that $\mathrm{M}_{23} \mathrm{C}_{6}$ precipitates are main the preferred nucleation site, leading to an uneven surface dissolution morphology $[23,24]$. Compared with wrought Hastelloy X (HX)samples, SLM-fabricated HX shows many nuclear sites of great compact passive film due to the higher low-angle GB (LAGB) density. This compact passive film contributed to improving surface quality to avoid starry corrosion 
during the ECM process at low current density in non-machining areas [25]. Some reports have shown that $\mathrm{AZ31} \mathrm{Mg}$ alloy and Ti-6Al-4V within a large amount of acicular $\alpha_{0}$ martensite resulted in preferentially anodic dissolution under low current densities [26]. Guo et al. [27] studied the electrochemical behaviors of laser solid forming-fabricated Inconel 718 and found that the $\gamma$ matrix around the Nb-rich $\gamma$ phase preferentially dissolved.

In this context, it offers theoretical guidance for selecting the appropriate electrolyte type and concentration through conducting open-circuit potential and potentiodynamic curves tests in ECM process. Secondly, current efficiency of wrought GH625 at different current density were tested, furthering exploring its material removal law at different current densities. Finally, effect of process parameters on the surface roughness of workpieces was analyzed and the optimized parameter combination was obtained according to single factor test.

\section{Experimental details}

\subsection{Processing principle}

Fig.1 shows image of fundamental principle on UAECG process. The cathode grinding head reams the processed small holes under high-frequency vibration and high-speed rotation, diamond abrasive grains are attached to the grinding head, and the anode workpiece is fixed on the worktable. In the UACEG process, the tool cathode and workpiece anode undergo electrolysis. The workpiece anode is dissolved in the electrolyte and form a passivation film. The spindle drives the abrasive particles to rotate at a high speed to scrape the passivation film and vibrate up and down under the action of ultrasound. Due to electrochemical dissolution, the grinding force and wear of the grinding head are greatly reduced. 


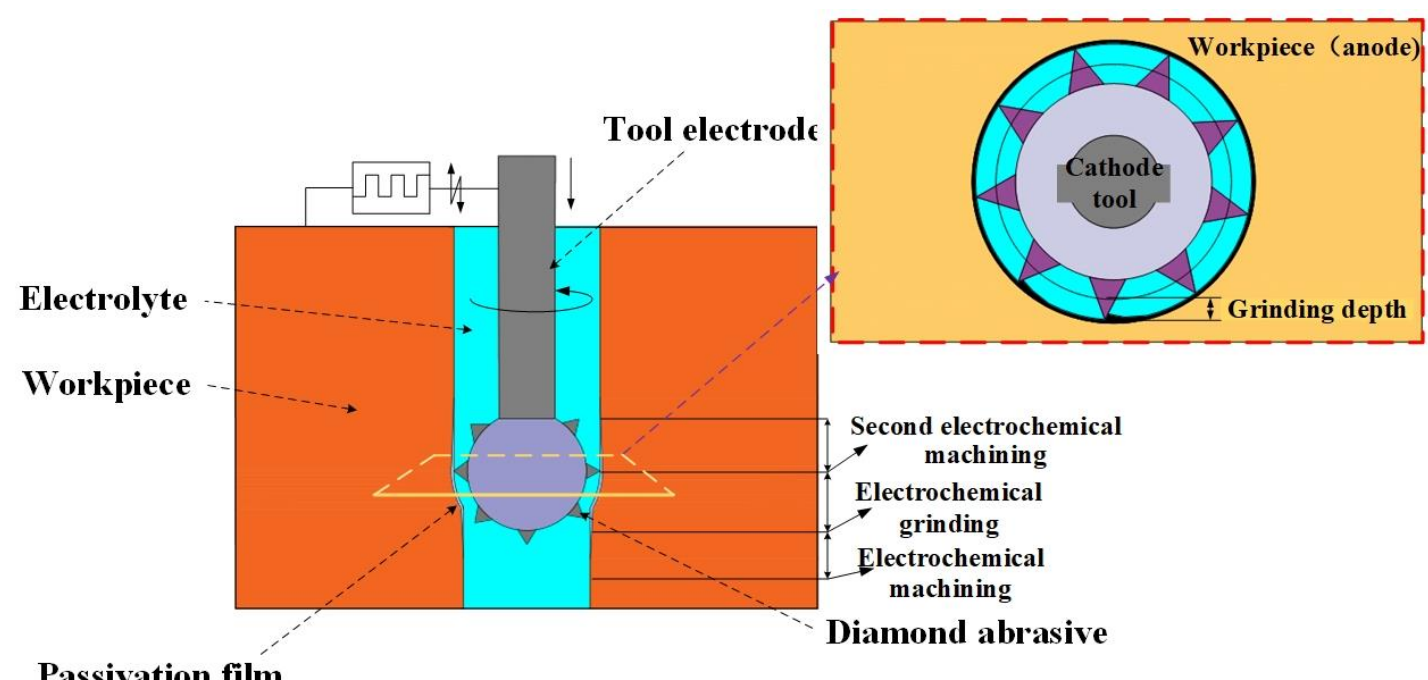

Fig 1. Schematic image of fundamental principle on UAECG process.

\subsection{Experimental set-up}

As shown in the Fig. 2, the tool cathode is connected to the negative electrode of the pulse power supply in UAECG process. The processed workpiece is taken as the positive electrode of the anode connection power supply, and the hydraulic pump supplies the electrolyte with certain pressure from the tool cathode to the processed workpiece, thereby forming a loop to realize the UAECG. The frequency of ultrasonic system is changed by programmable frequency converter in NC control system. In addition, high-precision motion control of three axes of machine tool by motion control card in NC control system. Machining voltage and interelectrode current is monitored using Hall current sensor monitors in real time. 


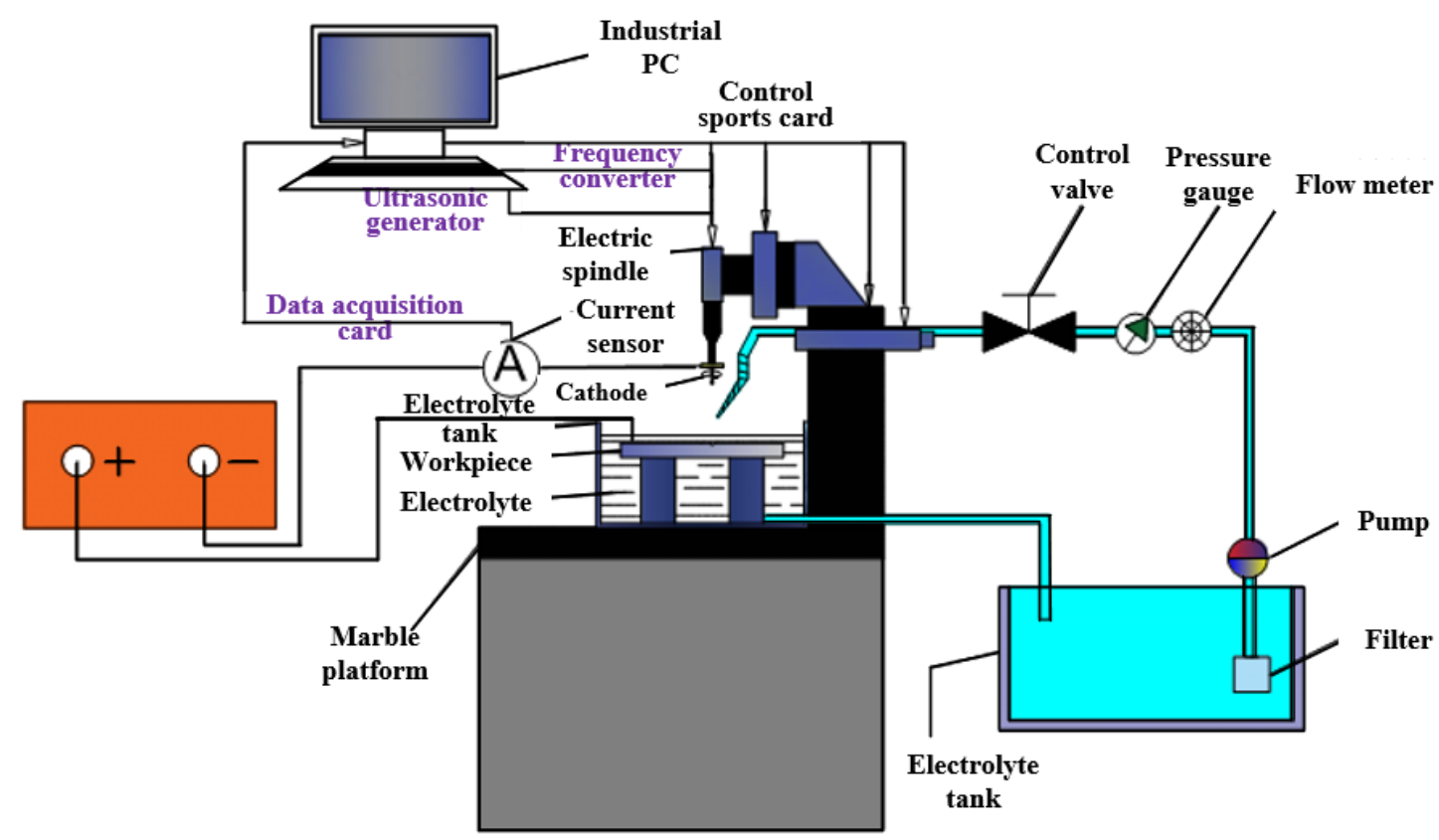

Fig 2. Schematic image of ultrasonic vibration assisted electrochemical grinding process

\subsection{Electrochemical measurement}

Determination of anodic polarization curves was carried out using a Corr Test electrochemical workstation (CS350, Wuhan, China). A platinum net and a calomel electrode were used as the counter-electrode and reference electrode, respectively. $\mathrm{NaNO}_{3}, \mathrm{NaClO}_{3}$ and $\mathrm{NaCl}$ solution was used as the electrolyte, and the surface air oxide film was removed by polarization for $2 \mathrm{~min}$ at a constant potential of $-1.2 \mathrm{~V}$ [24]. All the tests were performed potentiodynamically with a scan rate of $1 \mathrm{mV} / \mathrm{s}$, starting from $-1.5 \mathrm{~V}$ to $1.5 \mathrm{~V}$.

\subsection{Design of experiment}

In the present study, the GH625 material was made into $30 \times 10 \times 2 \mathrm{~mm}^{3}$ long squares. The surface of specimen was successively ground using SiC papers with grain sizes of 350 \#, cleaned and blown dry. Small holes were drilled on the specimens by tube electrode in UAECG experiment. The influence of each processing parameter on the processing accuracy and surface quality was studied, and high processing accuracy and 
surface quality were achieved by the optimization of processing parameters.

Table 1.

\begin{tabular}{|c|c|}
\hline Process parameters & Value or condition \\
\hline Spindle speed $V_{n}(\mathrm{kr} / \mathrm{min})$ & 1111.51212 .5 \\
\hline Feed rate $\mathrm{V}_{\mathrm{f}}(\mathrm{mm} / \mathrm{min})$ & $\begin{array}{llll}0.55 & 0.60 & 0.65 & 0.70\end{array}$ \\
\hline Pulse voltage $U_{m} / V$ & $\begin{array}{llll}5 & 5.8 & 6.6 & 7.2\end{array}$ \\
\hline Drive amplitude $\quad \%$ & $\begin{array}{llll}60 & 70 & 80 & 90\end{array}$ \\
\hline Pulse period $\mathrm{T} / \mu \mathrm{s}$ & 8 \\
\hline Duty cycle $\%$ & 50 \\
\hline Electrolyte pressure $\mathrm{P} / \mathrm{MPa}$ & 0.5 \\
\hline Number of grinding heads /\# & 800 \\
\hline Electrolyte concentration wt. \% & $10 \%$ \\
\hline
\end{tabular}

\subsection{Current efficiency curve measurement}

The current efficiency experiment device is shown in Fig. 2. It was made of epoxy resin with good airtightness. The two insulating chassis grooves of different sizes in the middle were respectively embedded in the cathode and anode parts. The anode specimen was a small cube of $10 \times 10 \times 10 \mathrm{~mm}^{3}$. The electrolytic surface was smoothed with 600-mesh sandpaper to remove the oxide scale, and then cleaned by ultrasonic cleaning. The current efficiency curve reflected the comprehensive characteristics of various reactions on the metal surface in electrochemical processing and the size of the electrolytic erosion ability. The removal quality was characterized by weight change of specimens.

Before the experiment, the specimen cubes need to be ultrasonically cleaned, blowdried and weighed. In each experiment, a stopwatch was used to precisely control the time. After the experiment, the specimens are weighed again. The current efficiency is calculated using the following formula:

$$
\eta=\triangle M \exp / \triangle M \text { Ltheo }=\triangle M \text { Ltheo } / k I t
$$

where $\Delta M \exp$ was the actual dissolved mass (g), $\Delta M L$ theo was the theoretical dissolved mass (g), $I$ was the external power supply current (A), $t$ was each dissolution time (s), and $k$ was the theoretical value of the mass electrochemical equivalent ( $\mathrm{g} / \mathrm{As}$ ), 
where $k$ could be obtained by the following formula.

$$
k=\frac{1}{\mathrm{~F}\left(\frac{n 1}{A 1} \alpha 1+\frac{n 2}{A 2} \alpha 2+\cdots+\frac{n q}{A q} \alpha q\right)}
$$

where $F$ was the Faraday constant, $n$ was the lower valence of a certain element dissolved, $A$ was the relative atomic mass of a certain element, $\alpha$ was the percentage of a certain element, and $q$ was the serial number.

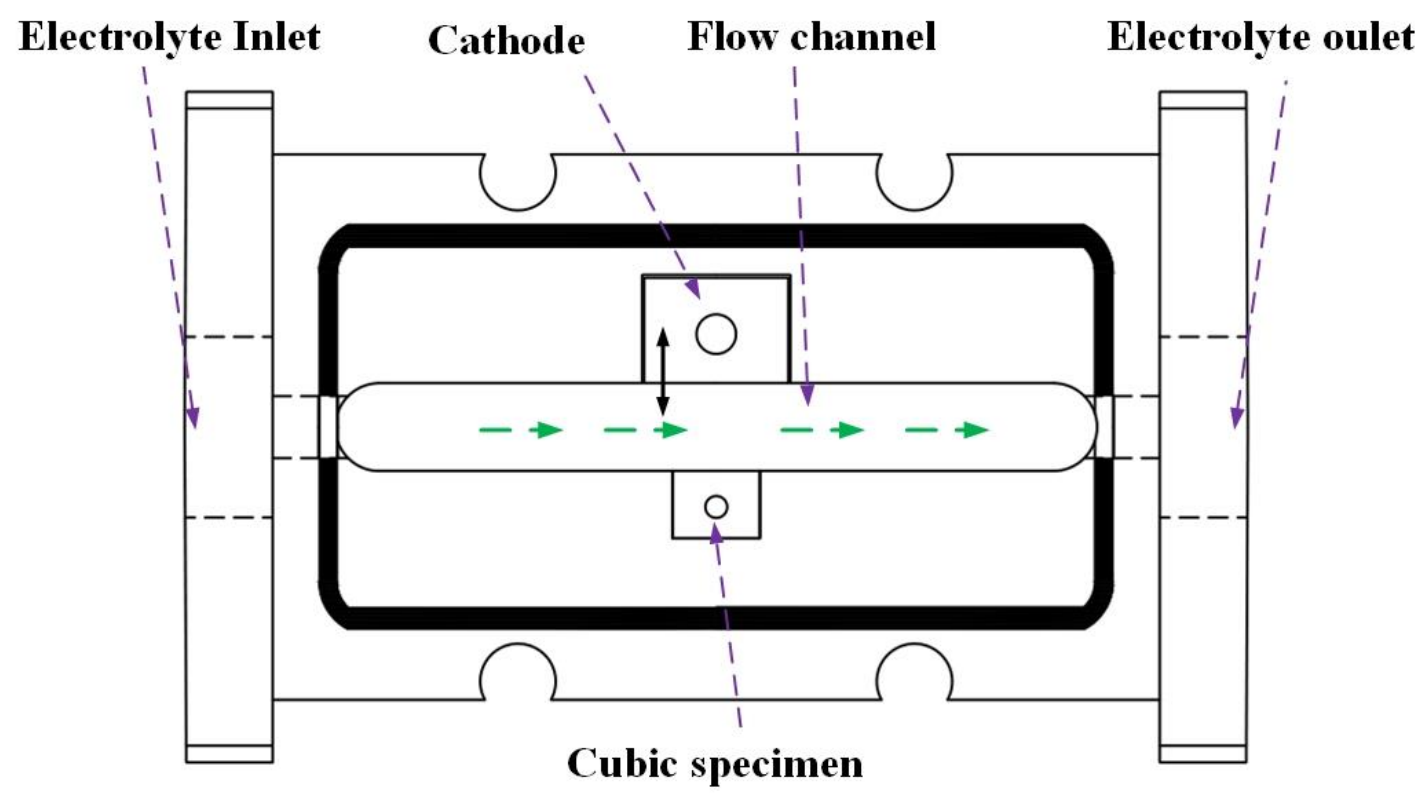

Fig 3. Schematic image of the experimental set-up on current efficiency.

\subsection{Microstructure characterization}

The microstructure components of the specimens were measured using EDS. The surface roughness, microstructure, and composition of the specimens machined at different current densities and corrosion times were investigated using a surface-finish instrument (Veeco NT9300), a scanning electron microscope (JEOL Corporation JSM7800F), and EDS (Oxford XMax-80).

\section{Results and discussions}

\subsection{Current efficiency curve}

The current efficiency curve reflects the comprehensive characteristics of various reactions on the matrix surface in electrochemical machining process, and also reveals the strength of the electrolytic erosion ability at different current density. The values of 
the current density ranged from 2 to $40 \mathrm{~A} \mathrm{~cm}^{-2}$, and the dissolution time was precisely controlled at different current density. The electrolyte used was a solution of $10 \mathrm{wt} . \%$ $\mathrm{NaNO}_{3}$ and its temperature was controlled at $20 \pm 1{ }^{\circ} \mathrm{C}$.

Plot of the $c e-j$ curve of GH625 in $10 \% \mathrm{NaNO}_{3}$ solution is displayed in Fig. 4. The current efficiency drops sharply with increasing current density, whereas its initial current efficiency rapidly reached more than $100 \%$ at low-current-density region. This might be due to the uneven composition and microstructure on the workpieces, thereby disrupting the compactness of the passivation film on the specimen surface to result in a high current efficiency at low current density [28, 29]. Meanwhile, large numbers of $\mathrm{NbC}$ carbides particles flaked off during the ECM process, contributing to high current efficiency at low current density.

When the current density exceeded $7.5 \mathrm{Acm}^{-2}$, the current efficiency curve of the specimens fluctuated slightly. This might be due to the fact that the current density increased to accelerate the dissolution rate of the workpieces. In the ECM process, there might be distributed uneven $\mathrm{NbC}$ particles on the grain boundary or in the grain for the GH625 matrix, preferably falling down intermittently in a non-electrochemical dissolution behavior. This thus resulted in the instability fluctuation of the efficiency curve in the high-current-density region [30]. 


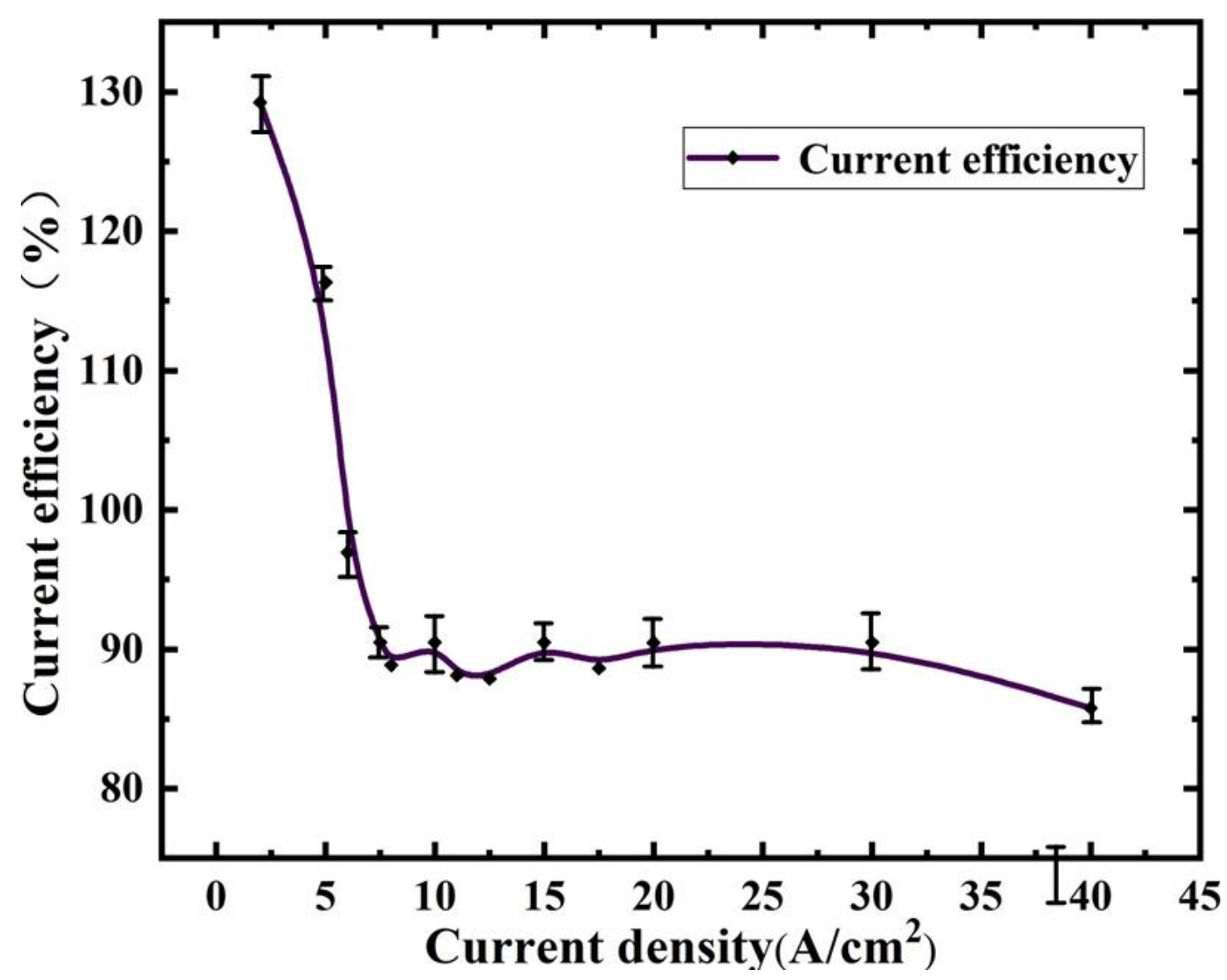

Fig 4. $c e-j$ curves of $\mathrm{GH} 625$ in $10 \mathrm{wt} . \% \mathrm{NaNO}_{3}$ solution

\subsection{Dissolution morphology analysis after electrochemical dissolution}

It can be clearly seen that the surface was covered with processed products and impurities in Fig.5, when a current density was $7.5 \mathrm{~A} / \mathrm{cm}^{2}$, according to the EDS analysis results, large particles with a length of $8 \mu \mathrm{m}$ with regular shapes were $\mathrm{NaNO}_{3}$ components in the electrolyte. In addition, many deep on the surface of the substrate pits caused bad surface quality due to the uneven corrosion at low current density. The formation of these little pits were primarily due to the preferentially corrosion around the carbides $(\mathrm{NbC})$ particles in the substrate and these carbides were washed away under the impact of the high-speed electrolyte, resulting in large numbers of small pits. This is consistent with the results of dramatic fluctuation for the efficiency curve as shown in Fig.4. 

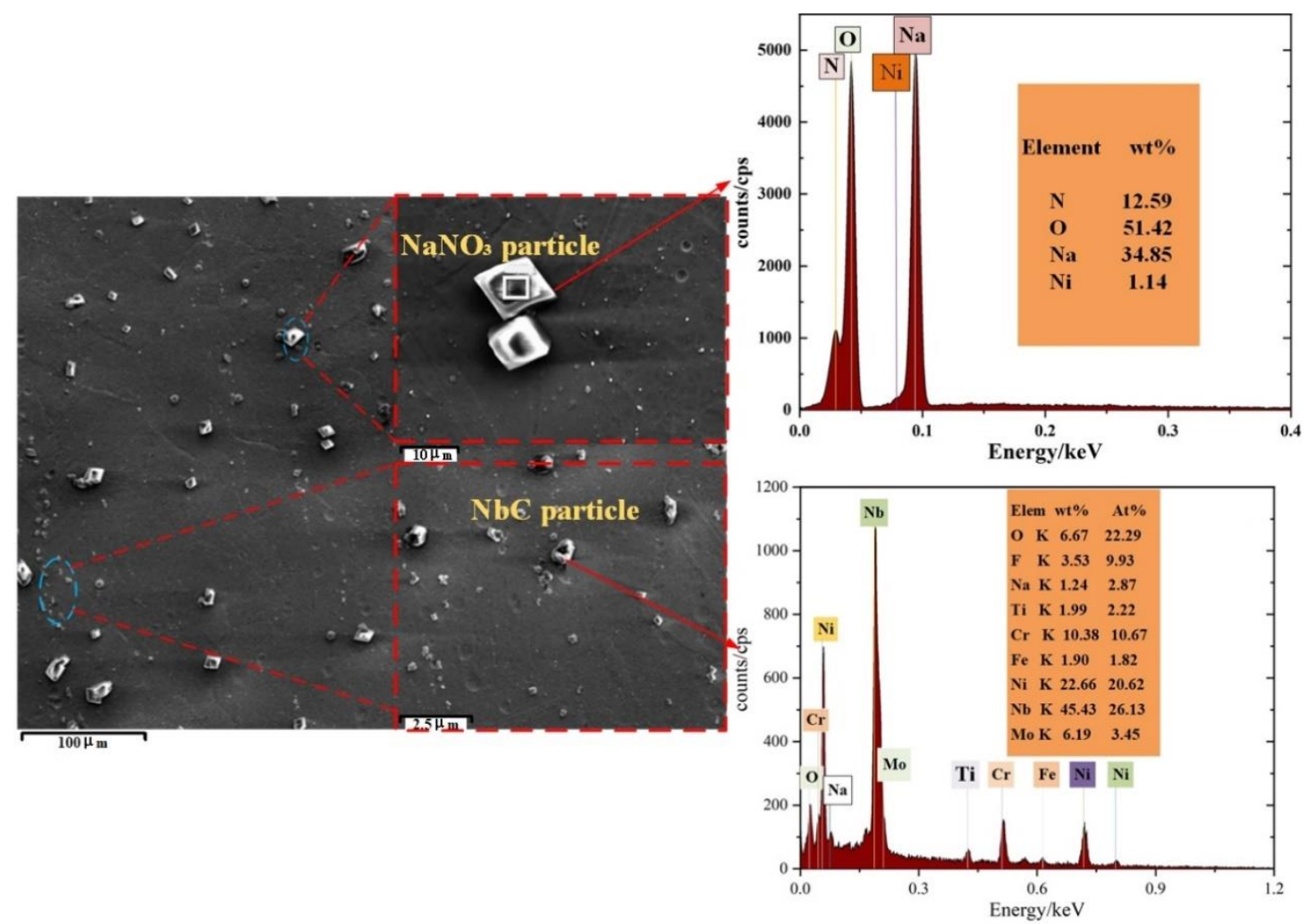

Fig 5. SEM and EDS results of the current density at $7.5 \mathrm{~A} / \mathrm{cm}^{2}$

The dissolution morphology of wrought GH625 at a current density of $12.5 \mathrm{Acm}^{-2}$ is shown in Fig. 6. The degree of electrolytic corrosion further increased, forming a series of small pits with shallow depth, and the residual impurities on the sample surface were significantly reduced. It can be seen from Figs. 6 and 7 that small pits were around the particles, a large number of sub-micron particles were unevenly distributed in the $\gamma$ matrix, and there were relatively large particles with a size of $1.25 \mu \mathrm{m}$. In the detection range of SEM-EDS, the larger particles were clearly identified as $\mathrm{NbC}$ carbides [31]. Since these particles were difficult to dissolve, they preferentially dissolve around the particles; these small particles were spherical, with slightly large sizes $(3.5 \mu \mathrm{m})$ distributed on the matrix. 


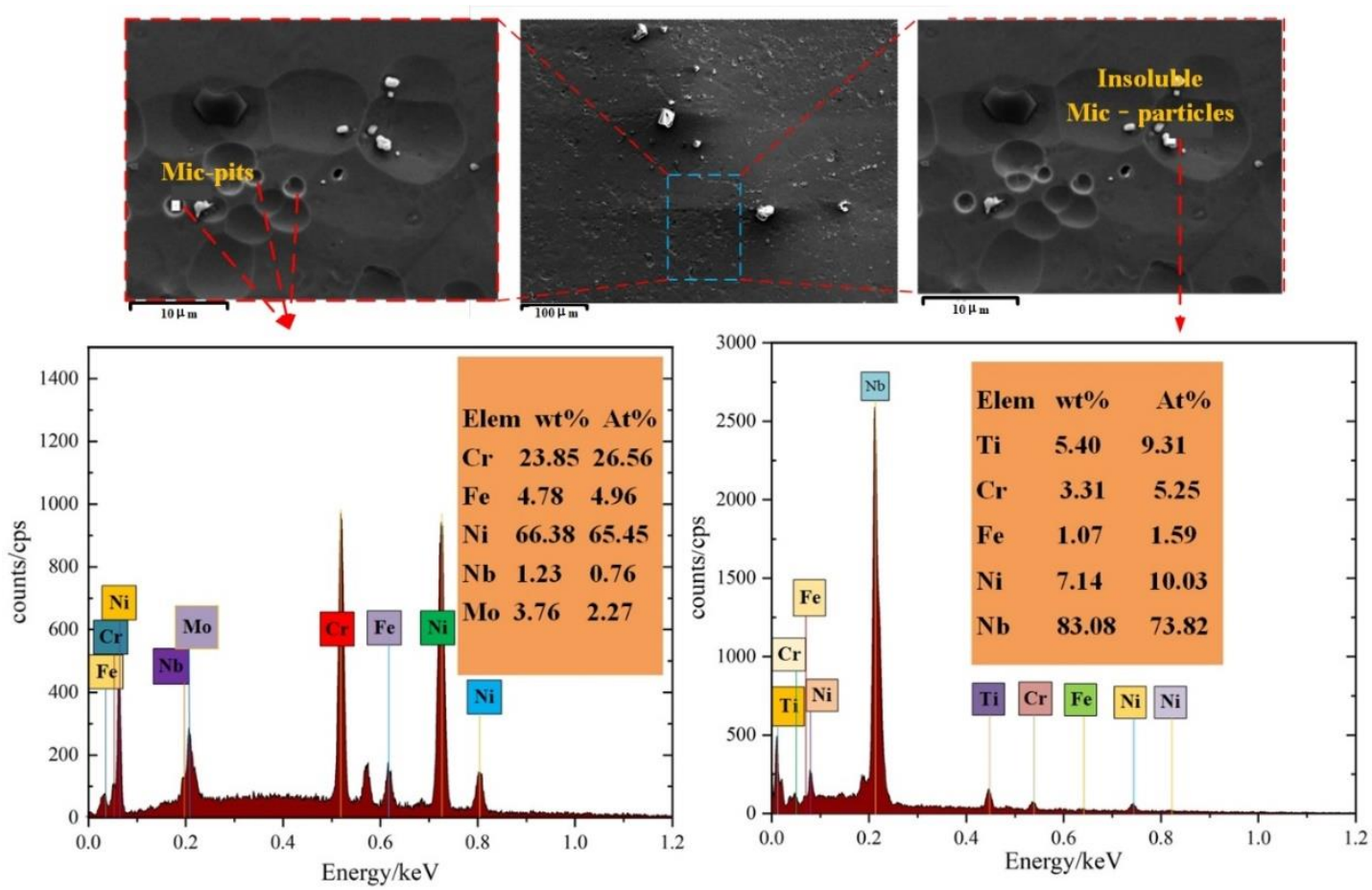

Fig 6.SEM and EDS results for the corroded specimens at $12.5 \mathrm{~A} \mathrm{~cm}^{-2}$

When a current density was $17.5 \mathrm{Acm}^{-2}$ during the electrochemical machining, it was found that there existed shallower small pits on the surface. This suggested that the surface quality was further improved with increasing current density. In addition, $\mathrm{NbC}$ particles with different shapes exhibiting from spherical to elongate were distributed the substrate surface.
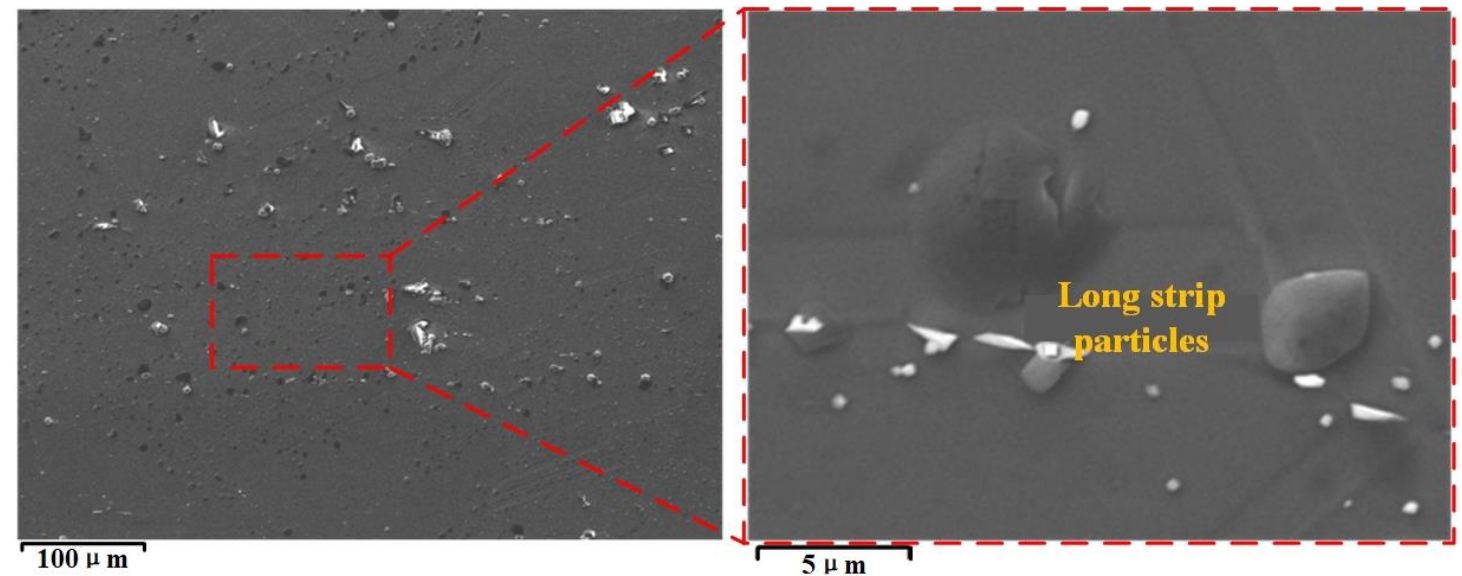

Fig 7. SEM results for the corroded specimens at $17.5 \mathrm{~A} \mathrm{~cm}^{-2}$

As seen from Figure.8, the primary components of the larger particles contained $\mathrm{Nb}$ elements, this was consistent with the analysis results in section 4.2. With increasing current density, some $\mathrm{NbC}$ particles had been exposed to the surface of the $\gamma$ substrate, 
and some were still covered by the substrate to form small bumps. Under the impact of the high-speed flow of electrolyte, the small bumps provided shelter for the flow of the substrate surface material; contributing to the formation of the larger bumps. It can be seen that the removal of the material on the $\gamma$ surface increased with current density increasing, and gradually expose the insoluble particles originally inside the matrix material.

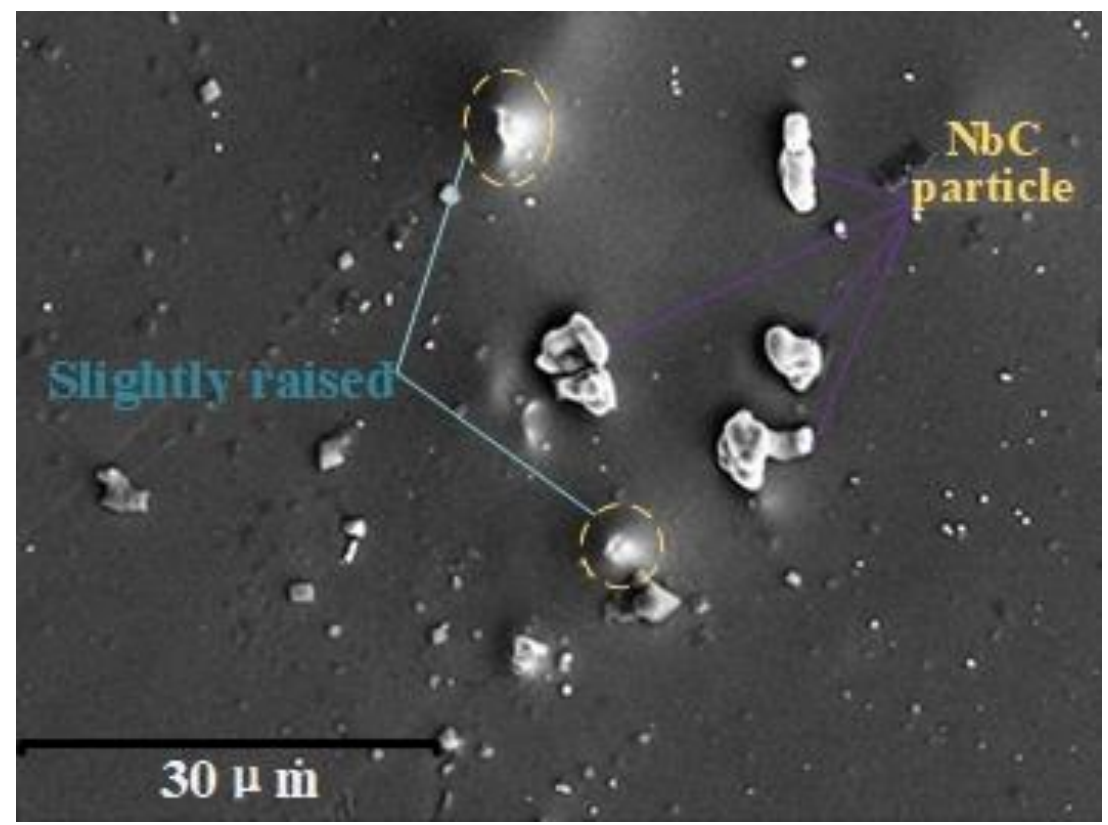

Fig 8. SEM results for the corroded specimens at $20 \mathrm{~A} \mathrm{~cm}^{-2}$

\subsection{Electrochemical dissolution behavior analysis}

The composition type, concentration and temperature of the electrolyte are taken into consideration for the significant factors to achieve stable and effective dissolution during the ECM process. As three general kinds of electrolytes, $\mathrm{NaNO}_{3}, \mathrm{NaCl}$, and $\mathrm{NaClO}_{3}$ electrolytes are widely used to study electrochemical dissolution behavior and thus selected primary solution in this work. 


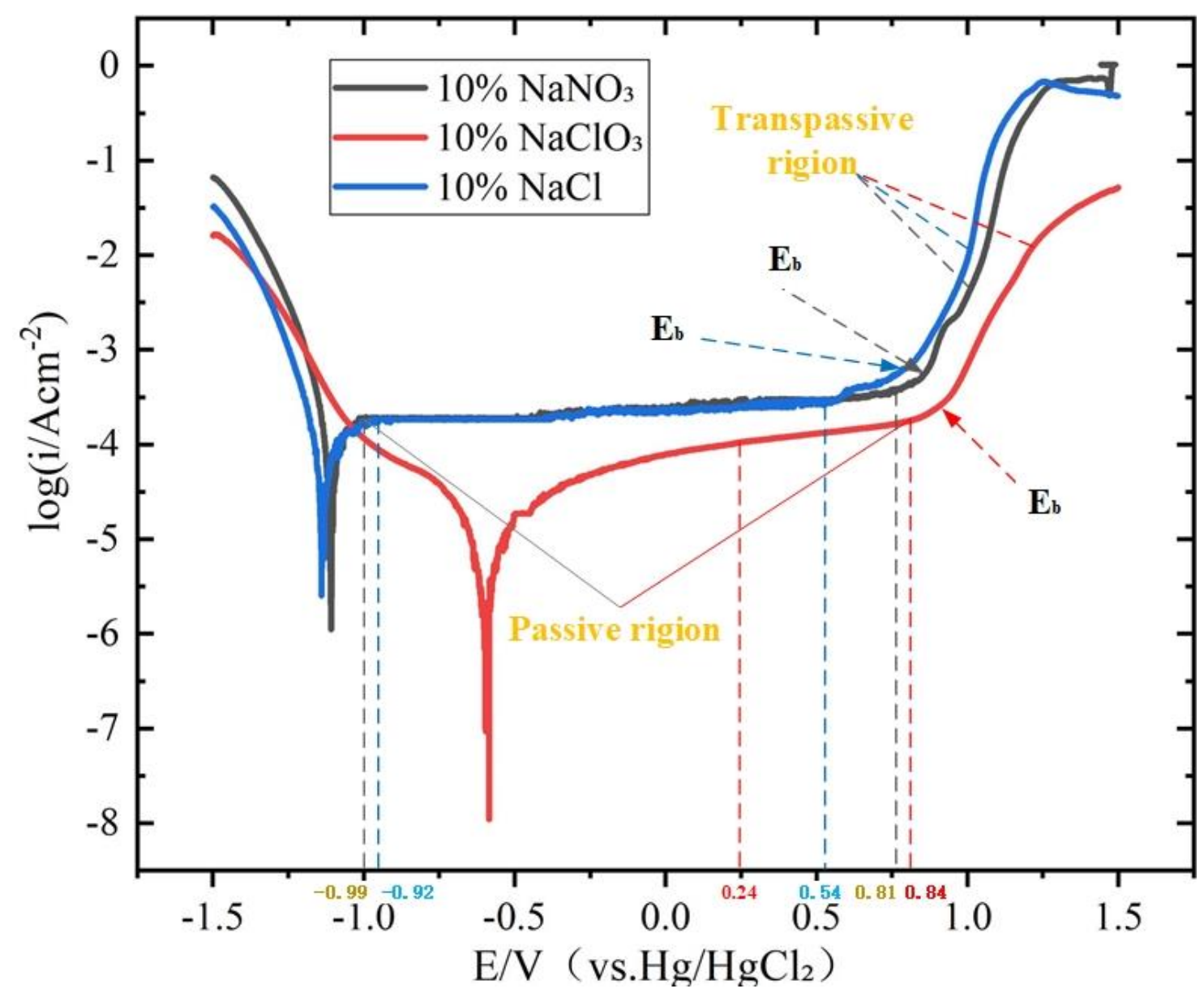

Fig 9. Polarization curves of GH625 in different concentrations of $\mathrm{NaNO}_{3}$ solution.

Plots of the polarization curves of GH625 in 10wt. \% $\mathrm{NaNO}_{3}, 10 \mathrm{wt} . \% \mathrm{NaCl}$ and 10wt. \% $\mathrm{NaClO}_{3}$ solutions are displayed in Fig. 9. In $\mathrm{NaNO}_{3}$ and $\mathrm{NaCl}$ electrolytes, a stable and smooth passivation zone is formed at a relatively low current density $\left(10^{-4}-\right.$ $10^{-3} \mathrm{~A} / \mathrm{cm}^{2}$ ), indicating that the passivation film is dense and unbroken. In the $\mathrm{NaClO}_{3}$ electrolyte of $-0.34-0.81 \mathrm{~V}$, the current density is lower than the other two electrolytes, but the current density increases with the increase of the potential, and there is an incomplete passivation zone; the figure shows that the passivation zone of $\mathrm{NaCl}$ and $\mathrm{NaNO}_{3}$ electrolytes is basically the same, but the current density of $\mathrm{NaNO}_{3}$ is slightly lower than that of $\mathrm{NaCl}$. This difference is attributed to the high affinity of $\mathrm{Cl}^{-}$ions and the low atomic radius. In addition, $\mathrm{NO}_{3}{ }^{-}$ions show stronger oxidation resistance than $\mathrm{Cl}^{-}$ions and $\mathrm{ClO}_{3}{ }^{-}$ions, which leads to a denser passivation film in $\mathrm{NaNO}_{3}$ solution. In the transpassive area of $\mathrm{NaNO}_{3}$ solution; as the current density increases, the anode electrochemical dissolution and oxygen evolution occur on the surface. When the anode 
potential exceeds $E_{b}$, the passivation film ruptures and peels off from the substrate. Neutral $\mathrm{NaNO}_{3}$ solution is widely used in the field of electrochemical machining because of its passivation properties, thereby improving machining accuracy. Through experiments, neutral electrolyte $\left(\mathrm{NaNO}_{3}\right)$ used different solutions to electrochemically cut low-carbon steel, and found that the cutting accuracy was better than that of sodium chloride in the $\mathrm{NaNO}_{3}$ electrolyte [32]. Therefore, $\mathrm{NaNO}_{3}$ solution can be used for achieving a precise electrochemical dissolution process.

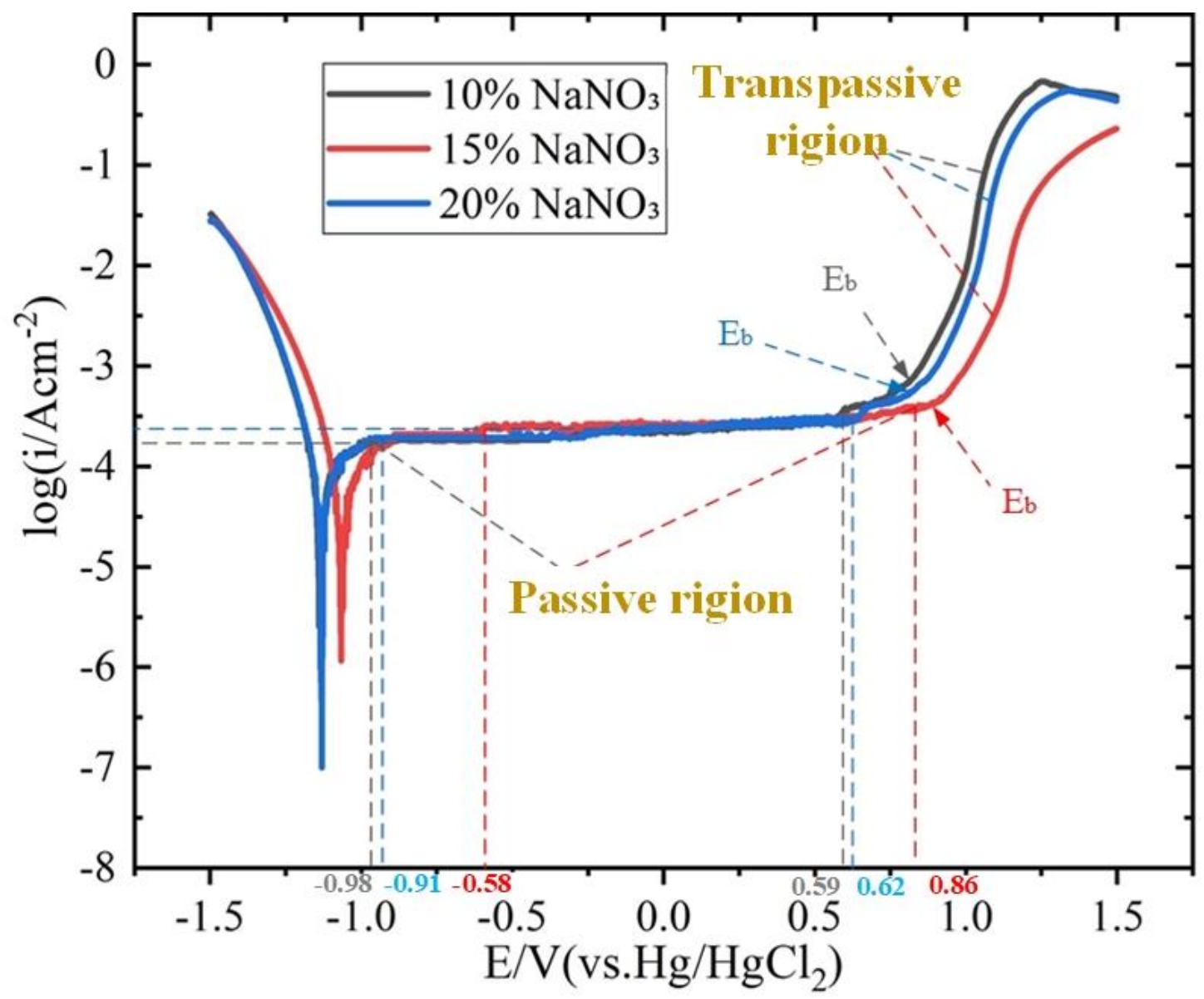

Fig 10. Polarization curves of GH625 at different concentrations in $\mathrm{NaNO}_{3}$ solution.

Polarization curve of GH625 at different concentrations (10 wt. \%, 20 wt. \% and 30 wt. \%) in $\mathrm{NaNO}_{3}$ solution as shown in Fig. 10. The dimensional passivation current density of 15 wt. $\% \mathrm{NaNO}_{3}$ is higher than the other two concentrations of electrolyte, and the dimensional passivation potential range is $-0.58-0.86 \mathrm{~V}$. The conductivity and ion exchange rate at the reaction interface accelerate, resulting in an increase in current density. The passivation effects of 10 wt. $\% \mathrm{NaNO}_{3}$ and 20 wt. $\% \mathrm{NaNO}_{3}$ are basically at the same level, but the passivation current density of $10 \mathrm{wt} . \% \mathrm{NaNO}_{3}$ is lower than 
that of 20 wt. $\% \mathrm{NaNO}_{3}$, and its passivation potential range is $-0.98-0.59 \mathrm{~V}$, which shows that at lower concentrations, the formation of high impedance and dense passivation films hinders the increase in current density. Therefore, 10 wt. $\% \mathrm{NaNO}_{3}$ can obtain effective and stable material removal.

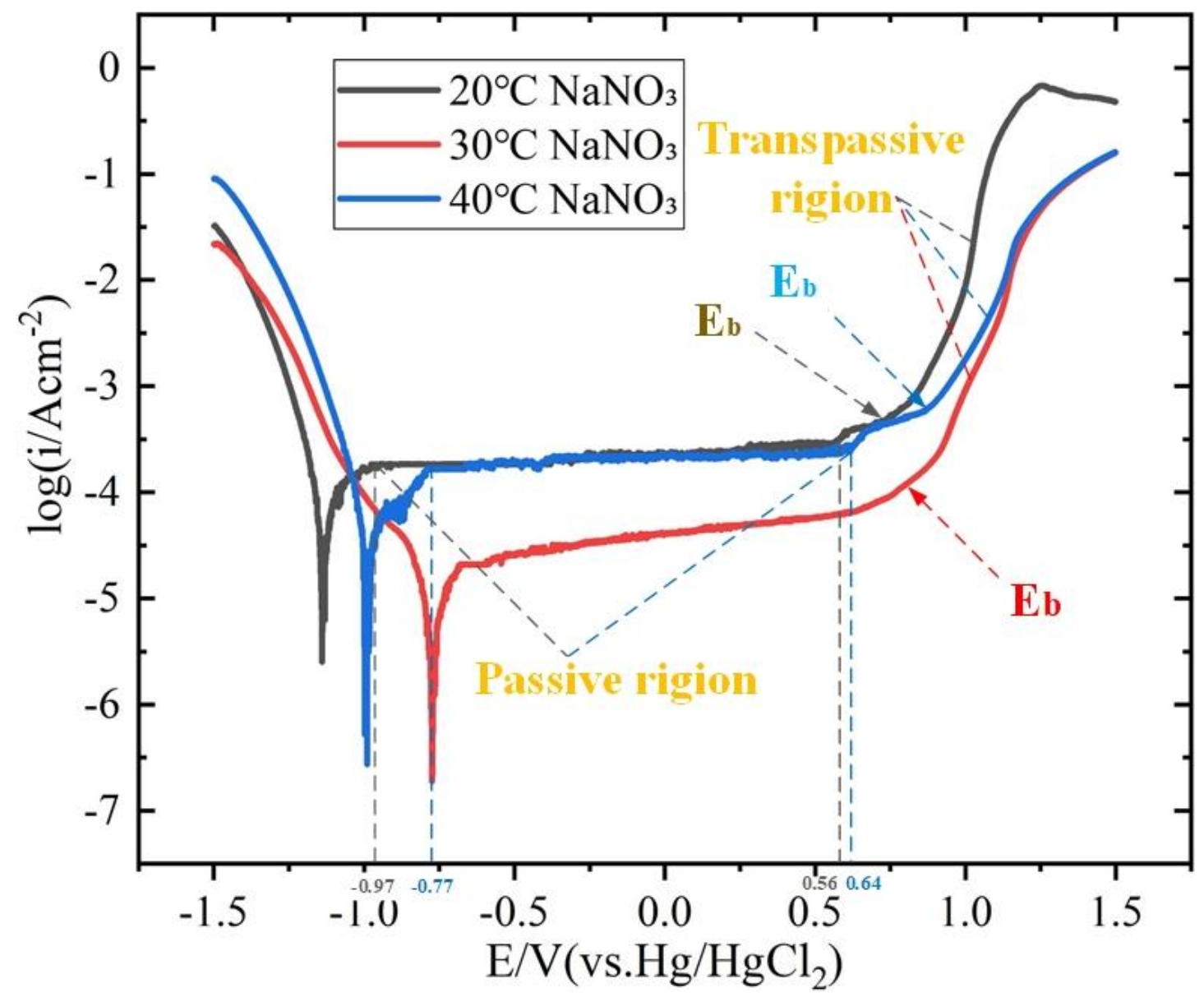

Fig 11. Polarization curves of GH625 at different temperatures in $\mathrm{NaNO}_{3}$ solution.

Polarization curve of GH625 at different temperatures $\left(20^{\circ} \mathrm{C}, 30^{\circ} \mathrm{C}\right.$ and $\left.40^{\circ} \mathrm{C}\right)$ in $\mathrm{NaNO}_{3}$ solution as shown in the Fig. 11. It can be clearly seen that the Fig. 11, the current density also increases with the increase of the potential at the temperature of $30^{\circ} \mathrm{C}$ in Fig.11, and there is an incomplete passivation interval. One possible explanation is that a higher electrolyte temperature leads to a higher percentage of activated molecules on the reaction interface further accelerating the intermolecular exchange rate. In addition, it can be observed that a clear passivation interval appeared at $20^{\circ} \mathrm{C}$ and $40{ }^{\circ} \mathrm{C}$, whereas there existed slight difference in passivation current density. However, the dimensional passivation potential range of $\mathrm{NaNO}_{3}$ is wider of $-0.97-0.56$ 
$\mathrm{V}$ at $20^{\circ} \mathrm{C}$, the dimensional passivation potential range of $40{ }^{\circ} \mathrm{C} \mathrm{NaNO}_{3}$ is $-0.77-0.64 \mathrm{~V}$.

According to the above analysis results, it is finally determined that an effective and stable material removal was obtained in $10 \mathrm{wt} . \% \mathrm{NaNO}_{3}$ electrolyte at $20{ }^{\circ} \mathrm{C}$.

\subsection{Effect of processing parameters on surface quality and taper}

\subsubsection{Effect of pulse voltage on surface quality and taper}

The influence of various processing factors on the surface roughness in the ultrasonicassisted electrochemical grinding and reaming processing in the following line chart of Fig.12. The selection of electrical parameters has remarkable influence on the surface quality and processing efficiency of the small holes. Thus, it is significant to select the power's parameters. Plots of four groups of different surface roughness and taper of GH625 in 10 wt. $\% \mathrm{NaNO}_{3}$ solution under different pulse voltages are displayed in Fig.

12. The surface quality was better when the pulse voltage was $5.8 \mathrm{~V}$, it was that lower pulse voltage formed the better surface quality. But the ultrasonic electrochemical grinding and erosion rate gradually slowed with increasing speed, which led to the formation of spark discharge on the surface of the specimens. And the formation of short circuits was due to the contact between the anode and the cathode, thereby affecting the surface quality of the small holes. At a constant feed rate, when the pulse voltage is too large, the ultrasonic assisted electrochemical grinding efficiency is improved, and the material removal rate is accelerated, resulting in continuous electrolysis of the machined surface.

Stray corrosion occurred on the surface as a result of the bad surface quality. Therefore, when the pulse voltage was $5.8 \mathrm{~V}$, the processing voltage was matched with other processing parameters to form a better surface quality. It could be found that the taper of the small hole increased with the increasing pulse voltage. Therefore, the most excellent roughness and taper were $0.456 \mu \mathrm{m}$ and $0.04446^{\circ}$ respectively with the suitable pulse voltage $(5.8 \mathrm{~V})$. 


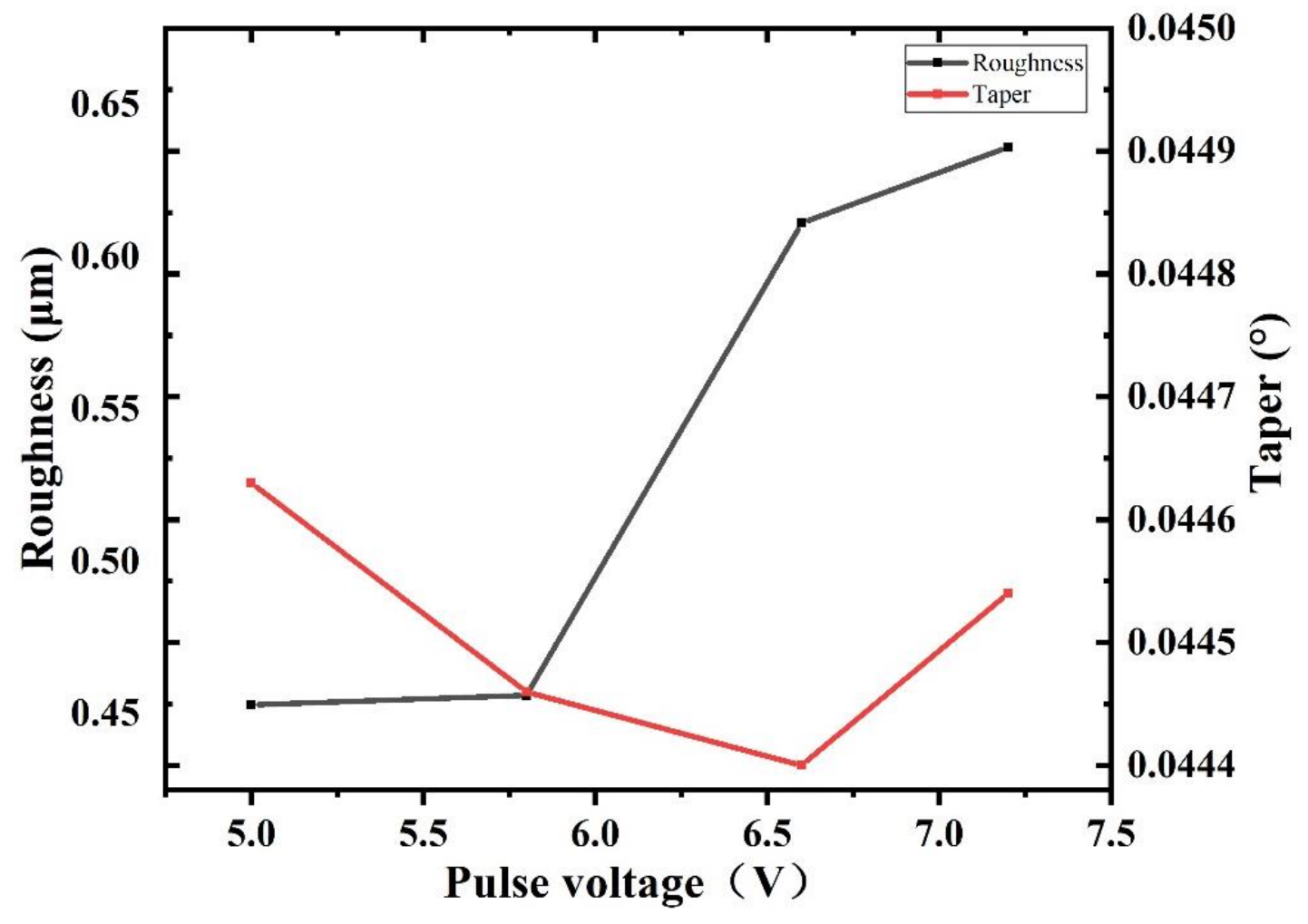

Fig 12. Effect of pulse voltage on surface roughness and taper

3.4.2 Effect of feedrate on surface quality and taper

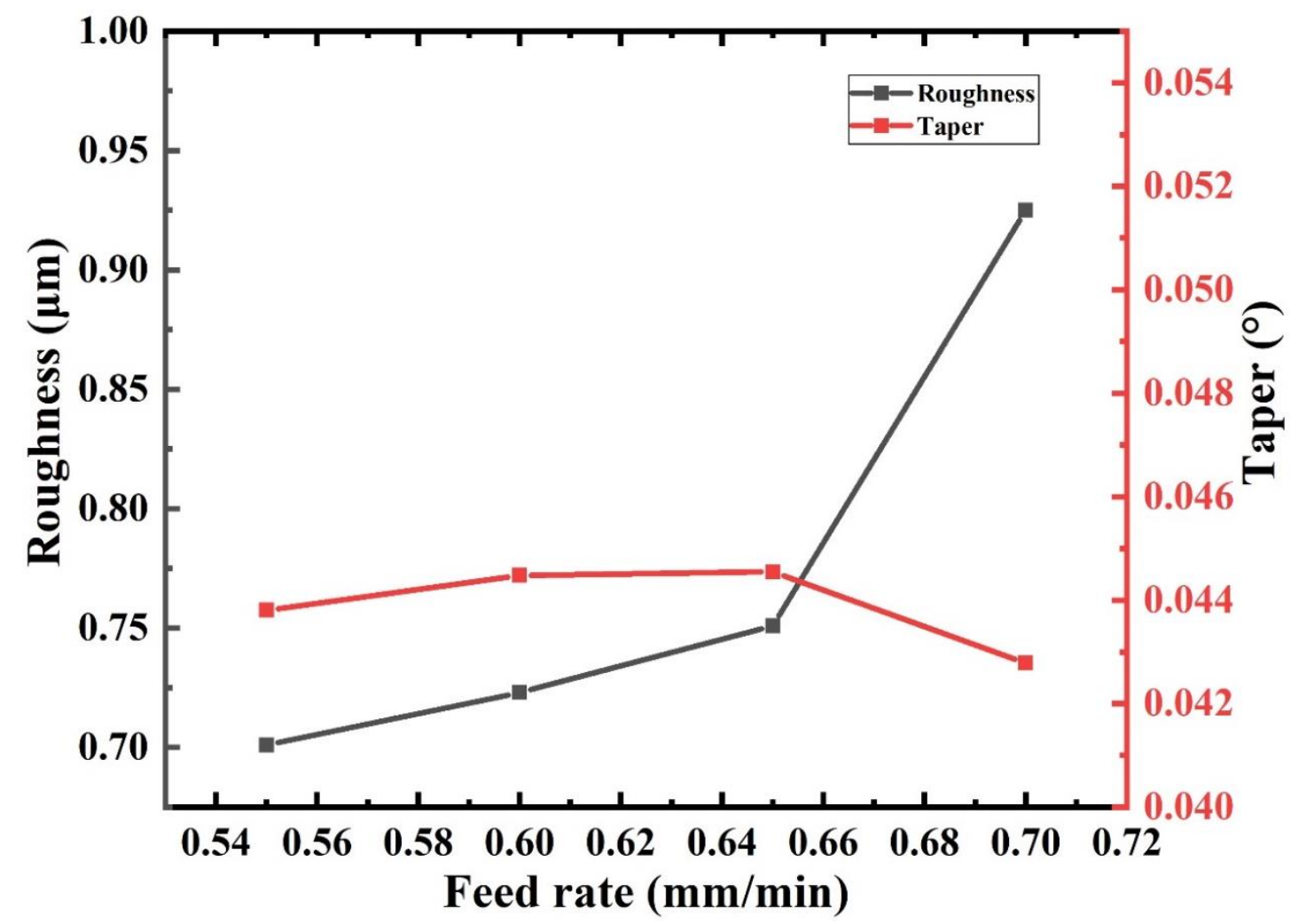

Figure 13. Effect of feedrate on surface roughness and taper 
In this section, the effect of feedrate on surface roughness and taper were studied in particular under the conditions of voltage of $5.8 \mathrm{~V}$, cathode speed of $12 \mathrm{kr} / \mathrm{min}$, drive amplitude of $60 \%$ and electrolyte pressure of $0.5 \mathrm{MPa}$, as shown in Fig. 13 the surface roughness of the small hole gradually increased with increasing feed speed. When a feed rate was $0.75 \mathrm{~mm} / \mathrm{min}$, it was difficult for cathode tool quickly electrolyzing the specimens, resulting in the occurrence of the short circuits. This was because that the machining product could not be ruled out timely. Therefore, the experimental results showed that better surface quality could be obtained under the processing parameters of $0.6 \mathrm{~mm} / \mathrm{min}$. Meanwhile, the taper of the small hole was $0.04381^{\circ}$ at a feed rate of $0.6 \mathrm{~mm} / \mathrm{min}$, and the taper was small, thus selected the feed rate of $0.6 \mathrm{~mm} / \mathrm{min}$.

\subsubsection{Effect of cathode speed on surface quality and taper}

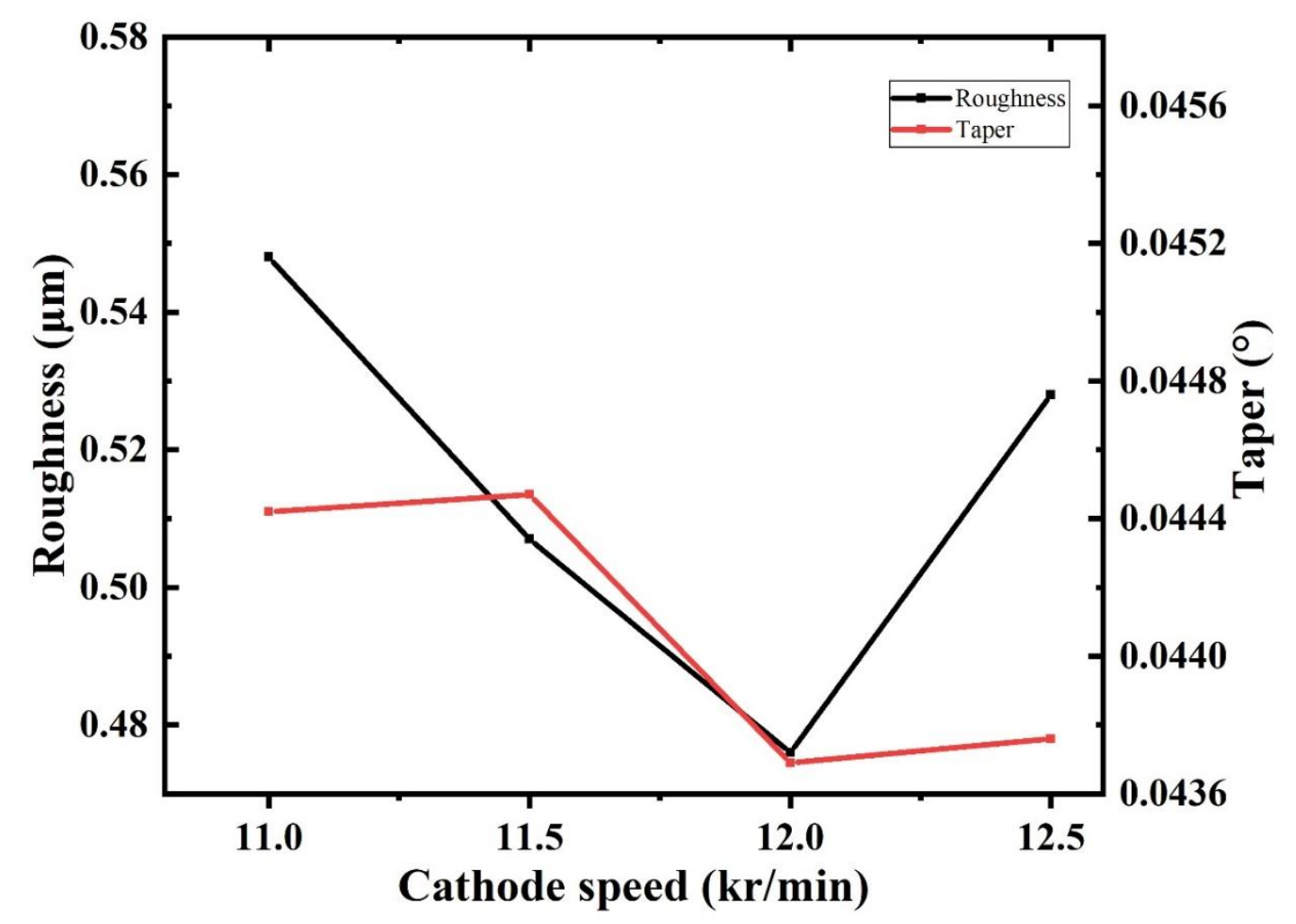

Fig 14. Effect of cathode speed on surface roughness and taper

Plots of roughness and taper of GH625 in $10 \mathrm{wt}$. $\% \mathrm{NaNO}_{3}$ solution under different cathode speeds are displayed in Fig. 14. The surface roughness first decreased and then increased with increasing cathode speed; and the surface roughness and taper in the holes were the lowest at a speed of $12 \mathrm{kr} / \mathrm{min}$, which was a surface roughness of 0.476 $\mu \mathrm{m}$ and a taper of $0.04369^{\circ}$. This was because that the tool was not enough to quickly 
grinded the processed material, resulting in a short circuit between the workpieces and tools. The material was quickly eroded away at a high speed for prolong electrolysis time, when the feed rate remained unchanged, resulting in reduced surface quality. On the other hand, the increase of cathode speed will also improve the flow field in the machining gap. Thus, the selection of a cathode speed of $12 \mathrm{kr} / \mathrm{min}$ was feasible.

\subsubsection{Effect of amplitude on surface quality and taper}

Fig. 15 shows the effect of the ultrasonic amplitude on the surface quality. The roughness of the small hole increased successively with increasing ultrasonic amplitude, and the roughness of small hole was $0.0464 \mu \mathrm{m}$ at an amplitude of $0.6 \mu \mathrm{m}$. The taper of small hole was $0.04127^{\circ}$ at an amplitude of $0.8 \mu \mathrm{m}$. However, the corresponding roughness was large and surface quality was poor. Therefore, it was better to choose the small hole processed by the drive amplitude of $60 \%$.

In summary, in terms of single-factor experiment method an excellent surface quality and minimum taper was successfully obtained at the pulse voltage of $5.8 \mathrm{~V}$, the feed speed of $0.6 \mathrm{~mm} / \mathrm{min}$, the rotation speed of $12 \mathrm{kr} / \mathrm{min}$ and the ultrasonic drive amplitude of $60 \%$.

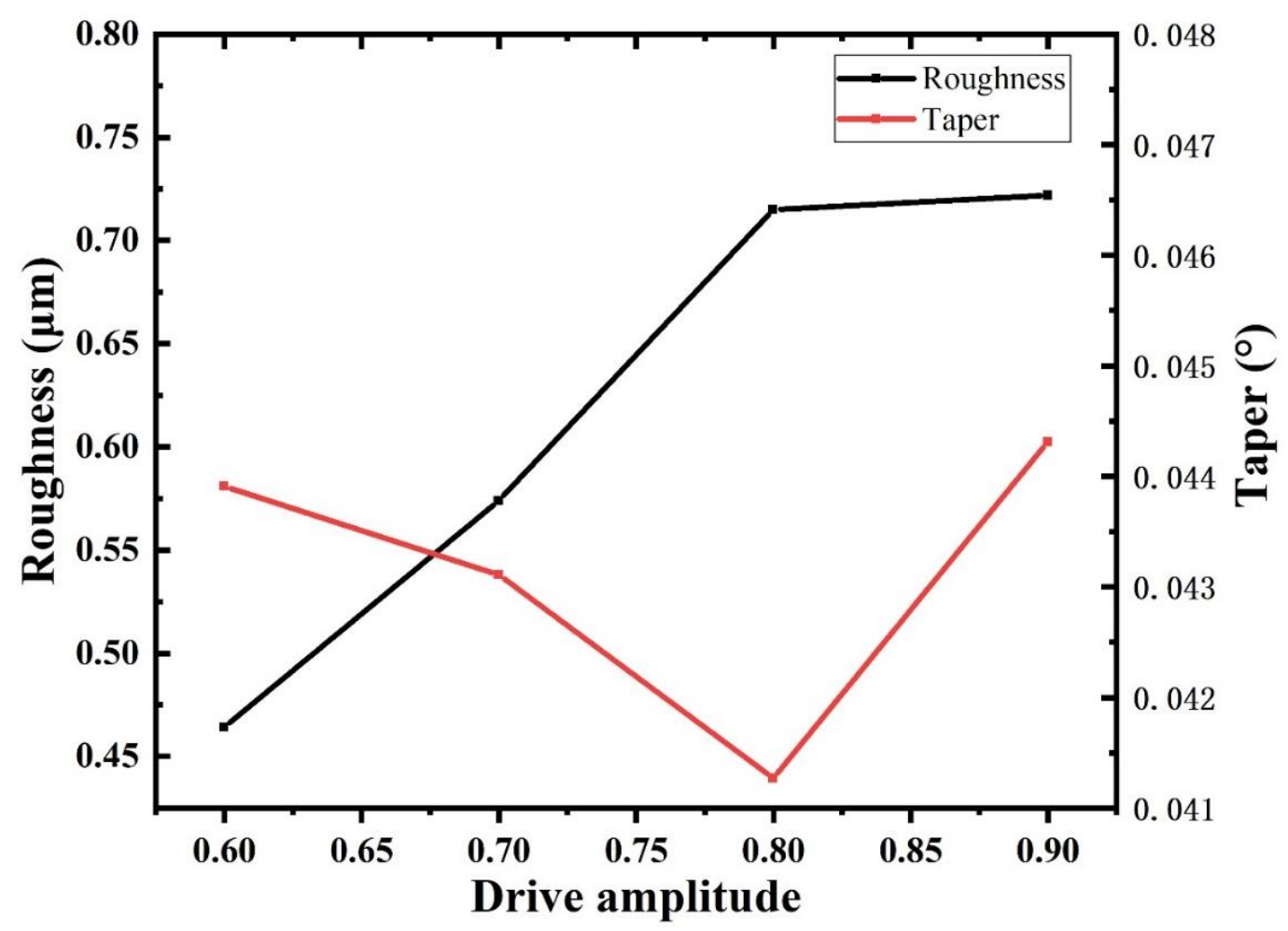


Fig 15. Effect of amplitude on surface quality and taper

\subsection{Comparative analysis of surface roughness between ECG and}

\section{UAECG}

In generally, low surface roughness can be obtained under the appropriate matching of electrochemical machining parameters and machining parameters. Based on above results, a comparative experiment of electrochemical grinding with or without ultrasonic vibration is carried out under the optimal processing parameters.

From the above figure, the surface roughness of $0.37 \mu \mathrm{m}$ can be obtained by electrochemical grinding with ultrasonic vibration, and the grain boundary is clearly visible. It was worth noticed that the difference between the import and export processing diameter is small. This is because cavitation and liquid mass transfer effect of ultrasonic vibration can make the processing process smoother and more stable; meanwhile, the electrolysis products and bubbles is discharged in time. The minimum surface roughness of electrochemical grinding without ultrasonic vibration is $0.5 \mu \mathrm{m}$, the difference between inlet and outlet is significant, and there is stray corrosion on the surface. This is mainly due to the increased electrochemical effect on the entrance surface, which causes short circuit of electrolysis products that are not discharged in time, and is formed by repeated processing many times. In addition, the secondary electrochemical effect leads to serious stray corrosion around the surface of workpieces. This affected the surface quality and average taper of the workpiece. There is no doubt that ultrasonic vibration plays an auxiliary role in the processing. 


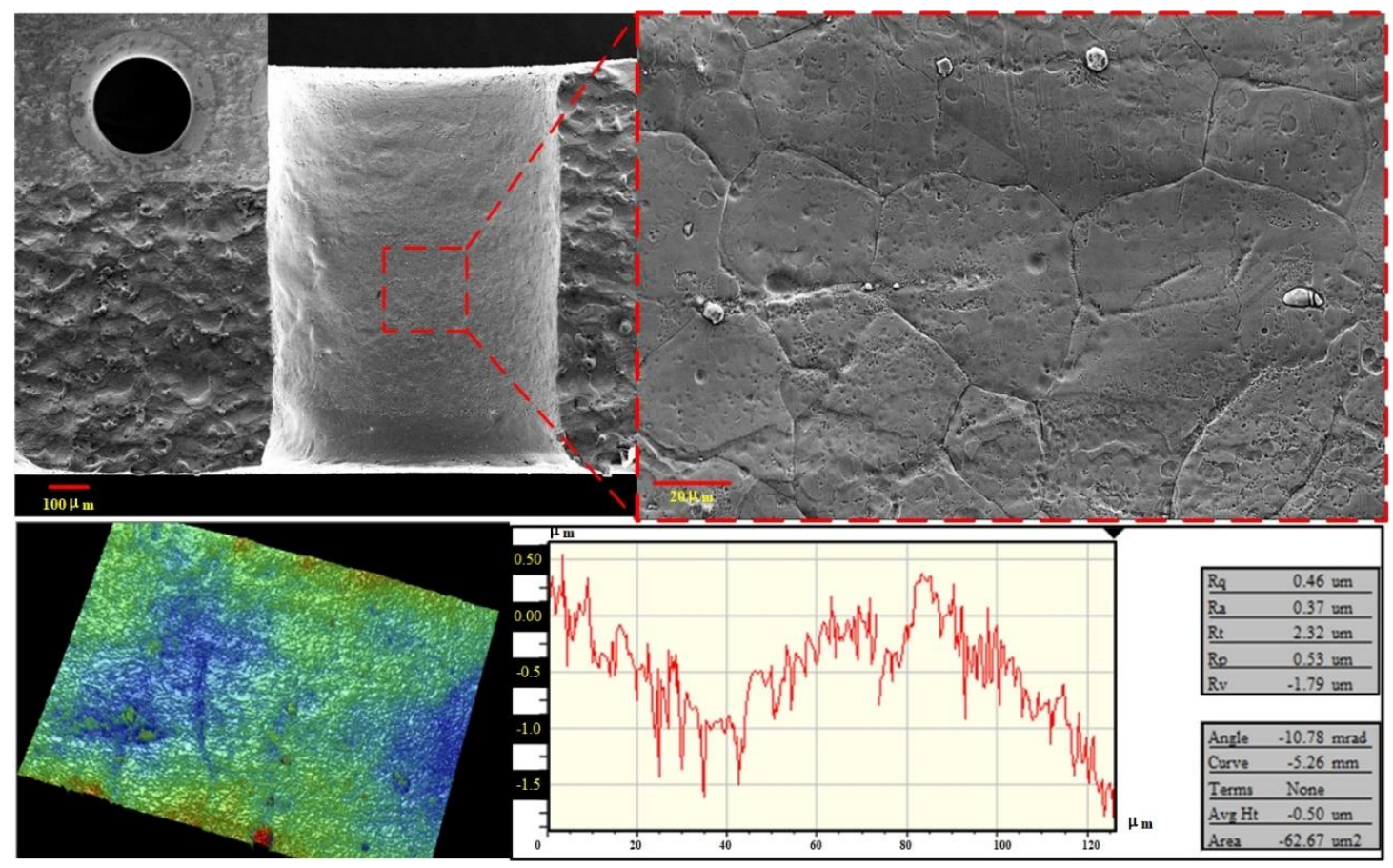

Fig 16. The experiment of UACEG with ultrasonic vibration

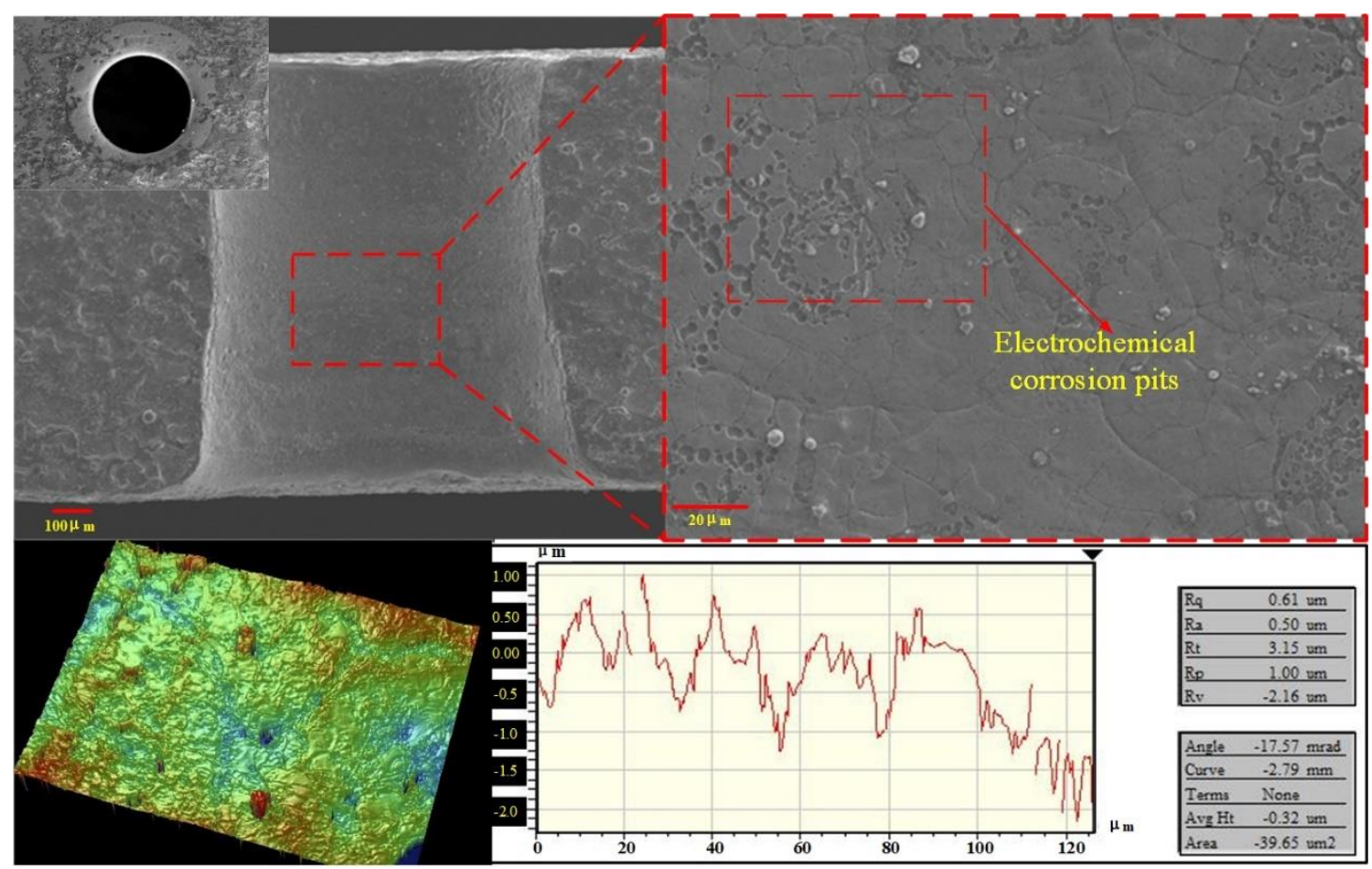

Fig 17. The experiment of UACEG without ultrasonic vibration 

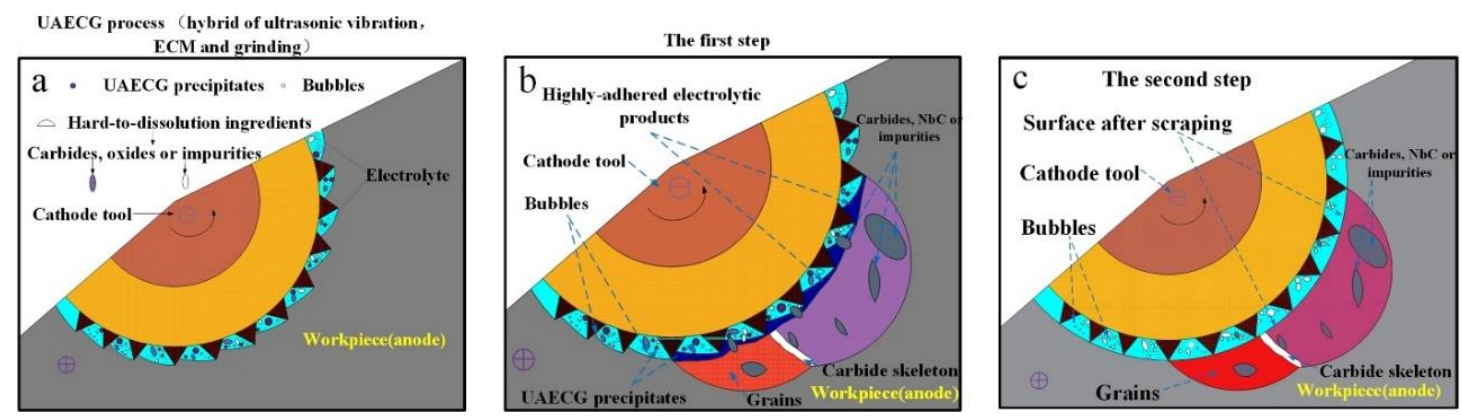

Fig 18. Schematic of material removal mechanism in ideal ECDG process

According to the experimental results discussed in section 3, a qualitative model is developed to explain the material removal mechanism of UAECG process. In the ultrasonic-assisted electrochemical grinding and reaming process, the metal atoms undergo oxidation reaction and lose electrons and become metal ions. On the surface of the tool cathode, the hydrogen ions in the electrolyte get electrons and undergo a reduction reaction to precipitate hydrogen gas. The electrochemical reactions on the anode surface of workpiece mainly include:

$$
\begin{aligned}
& \mathrm{Ni} \rightarrow \mathrm{Ni}^{2+}+2 \mathrm{e}^{-} \quad \mathrm{Ni}^{2+}+2 \mathrm{OH}^{-} \rightarrow \mathrm{Ni}(\mathrm{OH})_{2} \downarrow \\
& \mathrm{Cr} \rightarrow \mathrm{Cr}^{3+}+3 \mathrm{e}^{-} \quad \mathrm{Cr}^{3+}+3 \mathrm{OH}^{-} \rightarrow \mathrm{Cr}(\mathrm{OH})_{3} \downarrow
\end{aligned}
$$

In the UAECG process, the material removal mechanism depends on among the matching of ultrasonic vibration, electrochemical machining and mechanical grinding. As shown in Fig. 18(b), under the electrochemical action, a dense passivation film formed on the surface of the workpiece. However, as the electrochemical action continues to increase, the passivation film becomes thick and the electrolysis is inhibited. Furthermore, high-speed rotation of the cathode causes bubbles to appear under negative pressure, the bubble collapse is generated instantly occurs the impact force cooperates with the mechanical grinding action to scrape the passivation film; and then expose new surface to continue electrolysis. The liquid phase fluid discharges the processed products in time to update the electrolyte. The three functions complement each other in the processing process, which improves the processing efficiency and accuracy.

Fig.18 (c) shows the surface after removing the passivation film. During the processing, the surface of the matrix exposes insoluble particles, thereby reducing the surface quality. Mechanical grinding is used to scrape the insoluble particles and further 
grinding to form a smooth and flat processing surface.

\section{Conclusion}

In this paper, a comprehensive machining technology (UAECG) with ultrasonic vibration as the auxiliary, electrochemical machining and mechanical grinding was proposed, and the material removal mechanism was studied in detail. The following conclusions can be drawn:

1. SEM analysis results showed that the $\gamma$ matrix was preferentially dissolved around the insoluble particles, EDS results demonstrated that insoluble particles were primarily $\mathrm{NbC}$ carbides distributed in the grain or on the grain boundries.

2. The quantitative comparison results showed that electrochemical dissolution in $\mathrm{NaNO}_{3}$ solution was more stable than that in $\mathrm{NaCl}$ and $\mathrm{NaClO}_{3}$ solution during the electrochemical dissolution process at low current densities. It was beneficial for obtaining a stable and efficient dissolution at appropriate temperature $\left(20{ }^{\circ} \mathrm{C}\right)$ and concentration $(10 \%)$ in $\mathrm{NaNO}_{3}$ solution.

3. Arising from observation of material removal phenomenon, it is found that the material removal mechanism of UAECG has remarkable differences in that of ECG process. A qualitative machining model was established to further reveal the machining mechanism of UAECG in the view of the micro perspective.

4. Compared with ECG process, excellent surface quality $(R \mathrm{a}=0.37 \mu \mathrm{m})$ and taper of the small holes (taper $=0.04 \pm 0.005^{\circ}$ ) were obtained at the optimized condition of pulse voltage of $5.8 \mathrm{~V}$, feed rate of $0.6 \mathrm{~mm} / \mathrm{min}$, cathode speed of $12 \mathrm{kr} / \mathrm{min}$ and ultrasonic drive amplitude of $60 \%$ by the UACEG.

\section{Data availability statement}

The raw/processed data required to reproduce these findings cannot be shared at this time as the data also forms part of an ongoing study. 


\section{CRediT authorship contribution statement}

Yucai Ma: Conceptualization, Methodology, Writing-original draft. Yingyue Yin: Validation, Supervision, Writing-review \& editing. Jianhua Zhang; Software, Investigation. Jinxing Huo: Software, Investigation.

\section{Declaration of competing interest}

The authors declare that they have no known competing financial interests or personal relationships that could have appeared to influence the work reported in this paper.

\section{Acknowledgements}

This study was supported by the National Key Research and Development Program of China (No.2018YFB1105900). The authors thank Prof. Ning song Qu who contributed to useful discussions regarding this study. The authors thank the technical support from Sinoma Institute of Materials Research (Guangzhou) Co., Ltd.

\section{References:}

[1] L Jiwon, Terne Mathieu r, Jun Sunyoung, Hong Hyun-Uk, Copin Etienne, Lours Philippe (2020) Heat treatments design for superior high-temperature tensile properties of Alloy 625 produced by selective laser melting. Mater. Sci. Eng. A-Struct. Mater. Prop. Microstruct. Process 790: 139720

[2] M Saoubi R, D Axinte, L. S. Soo (2015) High performance cut-ting of advanced aerospace alloys and composite materials. CIRP Ann-Manuf. Technol 64 (2): 557-580

[3] Harpreet Singh, Pramod K Jain, Part B (2018) Study on ultrasonic-assisted electrochemical honing of bevel gears. Proc. Inst. Mech. Eng. Part B-J. Eng. Manuf 232 (4): 705 -712

[4] Li Si Si, Wu Yong Bo, Nomura Mitsuyoshi (2016) Fundamental Investigation of Ultrasonic Assisted Pulsed Electrochemical Grinding of Ti-6Al-4V. Materials Science Forum 874: 279-284

[5] N. A. Prasanth, L. J. Yuan, H. S. Yeo (2020) Multi-jet hydrodynamic surface finishing and X-ray computed 
tomography (X-CT) inspection of laser powder bed fused Inconel 625 fuel injection/spray nozzles. J. Mater. Process. Technol 291: 117018

[6] B Lauwers, F Klocke, A Klink, (2014) Hybrid processes in manufacturing. CIRP Ann-Manuf. Technol 63 (2): 561-583

[7] Z. Z. G. V. Dhokia, A Nasseh, (2013) A review of hybrid manufacturing processes -state of the art and future perspectives. Int. J. Comput. Integr. Manuf 26 (7): 596-615

[8] D. Zhan, L. Han, J. Zhang, Q. He, Z.-W. Tian, Z.-Q. Tian (2017) Electrochemical micro/nanomachining: Principles and practices. Chem. Soc. Rev 46 (5): 1526-1544

[9] L. Meng, Y. Zeng, D. Zhu (2017) Investigation on wire electrochemical micro machining of Ni-based metallic glass. Electrochim. Acta 233: 274-283

[10] M. Datta, IBM J (1998) Microfabrication by electrochemical metal removal. Res. Dev. 42 (5): 655-669

[11] A. De Silva, J.A. McGeough, J (1998) Process monitoring of electrochemical machining. Mater. Process. Technol 76: 165-169

[12] D. Zhan, L. Han, J. Zhang, K. Shi, J.-Z. Zhou, Z.-W. Tian, Z.-Q. Tian (2016) Confined chemical etching for electrochemical machining with nanoscale accuracy. Accounts Chem. Res 49 (11): 2596-2604

[13] A. R. Mount, P. S. Howarth, D. Clifton (2001) The use of a segmented tool for the analysis of electrochemical machining. J. App. Electrochem 31 (11): 1213-1220

[14] Z. Zhu, D. Wang, J. Bao, N. Wang, D. Zhu (2015) Cathode design and experimental study on the rotate-print electrochemical machining of revolving parts. Int. J. Adv. Manuf. Technol 80: 1957-1963

[15] Schuster R. Kirchner V, P Allongue (2000) Electrochemical micromachining. Science 289 (5476): 98-101

[16] H. S. Ahn, H. S. Ryu, K. D. Choi (2004) Electro-chemical micro drilling using ultra short pulses. Pre. Eng 28 (2): 129-134

[17] D.S. Bilgi, R.Kumar, V.K. Jain (2008) Predicting radial overcut in deep holes drilled by shaped tube electrochemical machining. Int. J. Adv. Manuf. Technol 39 (1-2): 47-54

[18] M. Lupak, S. Zaborski (2009) Simulation of energy consumption in electrochemical grinding of hard-to-machine materials. J. Appl. Electrochem 30 (1): 101-106

[19] S AGARWAL (2015) On the mechanism and mechanics of material removal in ultrasonics machining. Int J Mach Tool Mnuf 96: 1-14

[20] Li S, Wu Y, Nomura M (2018) Fundamental Machining Characteristics of Ultrasonic-Assisted Electrochemical Grinding of Ti6Al4V. J. Manuf. Sci. Eng.-Trans. ASME 140 (7): 071009 
[21] Li S, Wu Y, Nomura M (2016) Fundamental investigation of ultrasonic assisted pulsed electrochemical grinding of Ti6Al4V. Materials Science Forum 4389: 279-284

[22] Wu Y, Li S, Nomura M (2017) Ultrasonic assisted electrolytic grinding of titanium alloy Ti6Al4V. Int. J. Nano. manuf 13 (2): 152-160

[23] Y. Yin, J. Zhang, Y. Ma, J. Huo, K. Zhao, X. Meng, Q. Han, J. Yin (2020) Electrochemical Dissolution Behavior of Nickel-Based Hastelloy X Superalloy at Low Current Densities. IEEE Access 8: 62714-62724

[24] Y. Yin, J. Zhang, S. Yang, T. Liu, Q. Han, Z. Zhang, H. Yang (2021) Effect of microstructure on the electrochemical dissolution behaviour of Hastelloy X superalloy processed by selective laser melting and heat treatments. Mater. Des 206: 109828

[25] Y. Yin, J. Zhang, J. Huo, K. Zhao, X. Zhu, Q. Han, Y. Ma, Z Fu, J. Yin (2020) Effect of microstructure on the passive behavior of selective laser melting-fabricated Hastelloy X in NaNO 3 solution. Mater. Charact., 165: 110375 [26] P. Guo, X. Lin, J. Xu, J. Li, J. Liu, and W. Huang (2017) Electrochemical removal of different phases from laser solid formed inconel 718. J. Electrochem. Soc 164 (7): 151-157

[27] P. Guo, X. Lin, W. Huang (2017) Columnar structure and electrochemical anisotropy of a nickel-based superalloy fabricated via laser solid forming. J. Appl. Electrochem 47: 1083 (2017).

[28] T. Haisch, E. Mittemeijer, J.W. Schultze (2001) Electrochemical machining of the steel 100Cr6 in aqueous $\mathrm{NaCl}$ and NaNO3solutions: Microstructure of surface films formed by carbides. Electrochim. Acta 47 (9): 10831090

[29] D. Wang, Z. Zhu, B. He, Y. Ge, D. Zhu (2017) Effect of the breakdown time of a passive film on the electrochemical machining of rotating cylindrical electrode in $\mathrm{NaNO}_{3}$ solution. J. Mater. Process. Technol 239: 251-257

[30] O. Weber, M. Weinmann, H. Natter, D. Bähre (2015) Electrochemical dissolution of cast iron in $\mathrm{NaNO}_{3}$ electrolyte. J. Appl. Electrochem 4 (6): 591-609

[31] Jiwon Lee, Mathieu Terner, Sunyoung Jun, Hyun-Uk Hong (2020) Etienne Copin, Philippe Lours, Heat treatments design for superior high-temperature tensile properties of Alloy 625 produced by selective laser melting. Mater. Sci. Eng. A-Struct. Mater. Prop. Microstruct. Process 790: 139720

[32] C. Rosenkranz, M.M. Lohrengel, J.W. Schultze (2005) Microscopic investigations of electrochemical machining of Fe in $\mathrm{NaNO}_{3}$. Electrochim. Acta 48 (20-22): 3203-3211 